\title{
Importance of the Electrolyte in Obtaining Porous Silicon and How It Modifies the Optical and Structural Proprieties: Optical and Microstructural Investigation
}

\author{
F. Severiano, ${ }^{1}$ G. García, ${ }^{2}$ L. Castañeda, ${ }^{1}$ M. Salazar Villanueva, ${ }^{3}$ and J. Flores Méndez ${ }^{4}$ \\ ${ }^{1}$ Escuela Superior de Ingeniería Mecánica y Eléctrica Unidad Ticomán, Instituto Politécnico Nacional, 07340 México City, DF, Mexico \\ ${ }^{2}$ CIDS-ICUAP, Benemérita Universidad Autónoma de Puebla, 14 Sur y Avenida San Claudio, Edificio 137, 72570 Puebla, PUE, Mexico \\ ${ }^{3}$ Facultad de Ingeniería, Universidad Autónoma de Puebla, Apartado Postal J-39, 72570 Puebla, PUE, Mexico \\ ${ }^{4}$ División de Estudios de Posgrado e Investigación, Maestría en Ciencias en Ingeniería Mecánica, Instituto Tecnológico de Puebla, \\ 72220 Puebla, PUE, Mexico
}

Correspondence should be addressed to F. Severiano; ohcnap007@hotmail.com

Received 12 August 2014; Revised 17 January 2015; Accepted 19 January 2015

Academic Editor: Neeraj Dwivedi

Copyright () 2015 F. Severiano et al. This is an open access article distributed under the Creative Commons Attribution License, which permits unrestricted use, distribution, and reproduction in any medium, provided the original work is properly cited.

The effect of using different electrolytes in the physical and optical properties of porous silicon was studied. To do this porous silicon (PS) samples photoluminescent in the visible range from (100) oriented $n$-type crystalline silicon prepared by anodic etching were obtained. The first electrolyte was composed of a mixture of hydrofluoric acid (HF) and ethanol $\left(\mathrm{CH}_{3}-\mathrm{CH}_{2}-\mathrm{OH}\right)$ in a ratio of $1: 2$, respectively. The second was composed of hydrofluoric acid (HF), ethanol $\left(\mathrm{CH}_{3}-\mathrm{CH}_{2}-\mathrm{OH}\right)$, and hydrogen peroxide $\left(\mathrm{H}_{2} \mathrm{O}_{2}\right)$ in a ratio of $1: 1: 2$, respectively. Raman scattering, photoluminescence (PL), gravimetry, scanning electron microscopy (SEM), and energy dispersive spectrometer (EDS) measurements on the PSL were carried out. Raman scattering showed that the disorder in the samples obtained with $\mathrm{H}_{2} \mathrm{O}_{2}$ is greater than in the samples obtained without this. The PL from PS increased in intensity with the incremental change in the anodization time and showed a blueshift. The blueshift of PL is consistent with the reduction in size of the silicon nanocrystallites. The sizes of nanocrystals were estimated to be $3.08,2.6$, and $2.28 \mathrm{~nm}$. The gravimetric analysis showed that the porosity increased with the incorporation of $\mathrm{H}_{2} \mathrm{O}_{2}$. SEM images (morphological analysis) showed an incremental change in the quantity and in the porous size.

\section{Introduction}

With the discovery of light emission from porous silicon (PS) made by Canham [1], the possibility of the use of silicon as an efficient light source became attractive due to the potential applications in optoelectronics [2] and electroluminescent devices [3], because this source would be compatible with the existing manufacturing infrastructure for ultra-large-scaleintegrated circuits. The PS is a form of silicon prepared by anodic etching of crystalline silicon (c-Si). There have been a few changes in the electrolytes used to obtain PS. Some works report the use of hydrogen peroxide in obtaining of luminescent samples of PS [2]. The observation of intense photoluminescence (PL) from PS has been studied because of the large blueshift of the observed radiations with respect to the bulk silicon band-gap energy. It has been proposed that the quantum confinement in crystallites [4] or wires [5] is at the origin of the luminescence in the visible range. There are many hypotheses to explain the origin of the photoluminescence. Some of these theories involve siloxenes [6], polysilanes, or hydrides [7] on the surface of PS. Another suggestion is that the dominant luminescent material is amorphous in nature [8]. The quantum confinement interpretation of the luminescence of PS is supported by the evolution of the luminescence intensity and peak position with anodic oxidation $[9,10]$ which could lead to a progressive reduction in nanostructure sizes. The confinement model also seems to be consistent with structural characterizations. From a theoretical point of view, many works have shown that confinement in wires [4] or dots [11] with typical sizes 
TABLE 1: Conditions for the PS preparation.

\begin{tabular}{lcc}
\hline Sample & $\begin{array}{c}\text { Anodization time } \\
(\text { min })\end{array}$ & Electrolyte \\
\hline M1 & 10 & $1: 2\left(\mathrm{HF} / \mathrm{CH}_{3}-\mathrm{CH}_{2}-\mathrm{OH}\right)$ \\
M2 & 15 & $1: 2\left(\mathrm{HF} / \mathrm{CH}_{3}-\mathrm{CH}_{2}-\mathrm{OH}\right)$ \\
M3 & 10 & $2: 1: 1\left(\mathrm{H}_{2} \mathrm{O}_{2} / \mathrm{HF} / \mathrm{CH}_{3}-\mathrm{CH}_{2}-\mathrm{OH}\right)$ \\
M4 & 15 & $2: 1: 1\left(\mathrm{H}_{2} \mathrm{O}_{2} / \mathrm{HF} / \mathrm{CH}_{3}-\mathrm{CH}_{2}-\mathrm{OH}\right)$ \\
\hline
\end{tabular}

under $6 \mathrm{~nm}$ could explain the important blueshift of the luminescence compared to bulk silicon. The lifetime of the luminescence and the decay mechanism of the luminescence are unclear. The influence of defects, in particular surface defects, on the luminescence needs to be studied. By defects, we mean the way the etched surface of the silicon wafer is changed due to the inclusion of hydrogen peroxide in the electrolyte. In this work, PS samples were prepared by anodic etching of (100) oriented n-type c-Si and the effect of two kinds of electrolytes in obtaining porous silicon layers (PSL) was analyzed. The first electrolyte was composed of a mixture of hydrofluoric acid ( $\mathrm{HF})$ and ethanol $\left(\mathrm{CH}_{3}-\mathrm{CH}_{2}-\mathrm{OH}\right)$ in a ratio of $1: 2$, respectively, and the second was composed of $\mathrm{HF}$, ethanol, and $\mathrm{H}_{2} \mathrm{O}_{2}$ in a ratio of $1: 1: 2$, respectively.

\section{Experimental Details}

Phosphorous doped n-type (100) oriented c-Si having a resistivity of $1-5 \Omega \mathrm{cm}$ was used to prepare PS. The samples were obtained by the conventional anodization method [12] with different electrolytes and under a constant current density of $35 \mathrm{~mA} / \mathrm{cm}^{2}$. The $\mathrm{c}-\mathrm{Si}$ wafers were illuminated with UV light during the anodization process in order to create electronhole pairs that are necessary to carry out the electrochemical attack. The conditions for the PS preparation employed in the present study are summarized in Table 1.

The first electrolyte was composed to a mixture of hydrofluoric acid (HF; Merck) (40\%) and ethanol $\left(\mathrm{CH}_{3}-\mathrm{CH}_{2}-\right.$ $\mathrm{OH}$; J. T. Baker) (99.98\%) in a ratio of $1: 2$, respectively, and the second was composed by a mixture of hydrofluoric acid (HF) (40\%), ethanol $\left(\mathrm{CH}_{3}-\mathrm{CH}_{2}-\mathrm{OH}\right)(99.98 \%)$, and hydrogen peroxide $\left(\mathrm{H}_{2} \mathrm{O}_{2} ; \mathrm{J}\right.$. T. Baker) $(30 \%)$ in a ratio of $1: 1: 2$, respectively. After the PS samples were obtained a laser with a wavelength of $405 \mathrm{~nm}$ and $40 \mathrm{~mW}$ of power was used to excite the sample in the PL measurements. The range detected by the monochromator was from 400 to $1100 \mathrm{~nm}$. The thickness and porosity of the PSL was estimated by gravimetry. The structural characterization was obtained by micro-Raman in a Dilor Labram spectrometer, with a He-Ne $(632 \mathrm{~nm})$ laser and using a 50x objective. The diameter of the laser beam spot at the focus plane is $=1 \mu \mathrm{m}$. A Philips brand XL30ESEM microscope was used to obtain surface morphology studies of the PSL. The chemical composition was obtained from the Energy Dispersive Spectrometer (EDS) coupled at system SEM.

\section{Results and Discussion}

3.1. Thickness and Porosity Obtained by Gravimetry. The thickness and the porosity of the PSL were estimated by gravimetry. In this process the porous layer was removed using a sodium hydroxide (99.95\%) and deionized water solution in a ratio of $1: 100$, respectively, in which the PS was immersed, and the porous layer is removed during contact with this solution. The porosity was calculated by means of the following equation [13]:

$$
P=\frac{m_{1}-m_{2}}{m_{1}-m_{3}},
$$

where $m_{1}$ is the mass of the wafer of c-Si before the attack, $m_{2}$ is the mass of the wafer after the anodization, and $m_{3}$ is the mass of the same wafer after removing the PSL. The thickness of the PSL was obtained by the expression [13]

$$
E=\frac{m_{1}-m_{3}}{\rho S_{a}},
$$

where $\rho$ is the density of the $\mathrm{c}-\mathrm{Si}$ (in $\mathrm{g} / \mathrm{cm}^{3}$ ) and $S_{a}$ is the attacked surface during the anodization (in $\mathrm{cm}^{2}$ ). Table 2 shows the results obtained by gravimetry. The gravimetric results showed an increase in the porosity of the samples that were obtained with hydrogen peroxide in the starting solution (M3, M4). In relation to the thickness of the porous layer, we can observe that an increase in porosity occurs. This behavior indicates that the hydrogen peroxide promotes the attack on crystalline silicon wafer and this attack takes place preferentially at the edges of the pores, which will be reflected in the increase of the pore diameter as we can see in the SEM images.

3.2. Raman Modes Analysis. Figure 1 shows Raman spectra from longitudinal optic (LO) phonon for all samples of PS in the range from 490 to $530 \mathrm{~cm}^{-1}$. In these spectra we can see the LO mode of c-Si $\left(512 \mathrm{~cm}^{-1}\right)$. Since c-Si is (100) cut, LO mode is allowed and transversal optic (TO) mode is forbidden. It is to be noted that the LO mode of PS broadens (503$518 \mathrm{~cm}^{-1}$ ), becoming asymmetric in comparison with that of c-Si $\left(508-515 \mathrm{~cm}^{-1}\right)$. Si nanocrystallites relax the wavevector selection rule, which causes the Raman spectrum to broaden and become asymmetric [14].

Right inset in the Figure 1 shows the Raman spectra for PS samples in the range of $900-1000 \mathrm{~cm}^{-1}$. M3 and M4 samples show a peak around $930 \mathrm{~cm}^{-1}$ which is due to disorder induced 2TO phonon overtones [15]. This mode arises due to the disorder present around the pores, and the disorder is formed during the anodization process. During the anodization, the attack process results in a layer of disordered (a-Si) around the pore, as will be seen in the SEM images. The possible disordered silicon layer would result in TO as well as $2 \mathrm{TO}$ mode appearance $\left(930 \mathrm{~cm}^{-1}\right)$. With the incorporation of hydrogen peroxide in the electrolyte, the disorder in the PSL increases and hence the 2TO mode intensity increases $\left(930 \mathrm{~cm}^{-1}\right)$. M1 and M2 samples barely show this mode since the rate of disorder is less than the samples obtained with 
TABLE 2: Gravimetric results of the different PS samples.

\begin{tabular}{lcccc}
\hline Sample & Anodization time $(\mathrm{min})$ & Electrolyte & Thickness $(\mathrm{m} \mu)$ & Porosity $(\%)$ \\
\hline M1 & 10 & $1: 2\left(\mathrm{HF} / \mathrm{CH}_{3}-\mathrm{CH}_{2}-\mathrm{OH}\right)$ & 38 & 40 \\
M2 & 15 & $1: 2\left(\mathrm{HF}_{2} / \mathrm{CH}_{3}-\mathrm{CH}_{2}-\mathrm{OH}\right)$ & 40 & 40 \\
M3 & 10 & $2: 1: 1\left(\mathrm{H}_{2} \mathrm{O}_{2} / \mathrm{HF}_{2} \mathrm{CH}_{3}-\mathrm{CH}_{2}-\mathrm{OH}\right)$ & 62 \\
M4 & 15 & $2: 1: 1\left(\mathrm{H}_{2} \mathrm{O}_{2} / \mathrm{HF} / \mathrm{CH}_{3}-\mathrm{CH}_{2}-\mathrm{OH}\right)$ & 60 & 62 \\
\hline
\end{tabular}

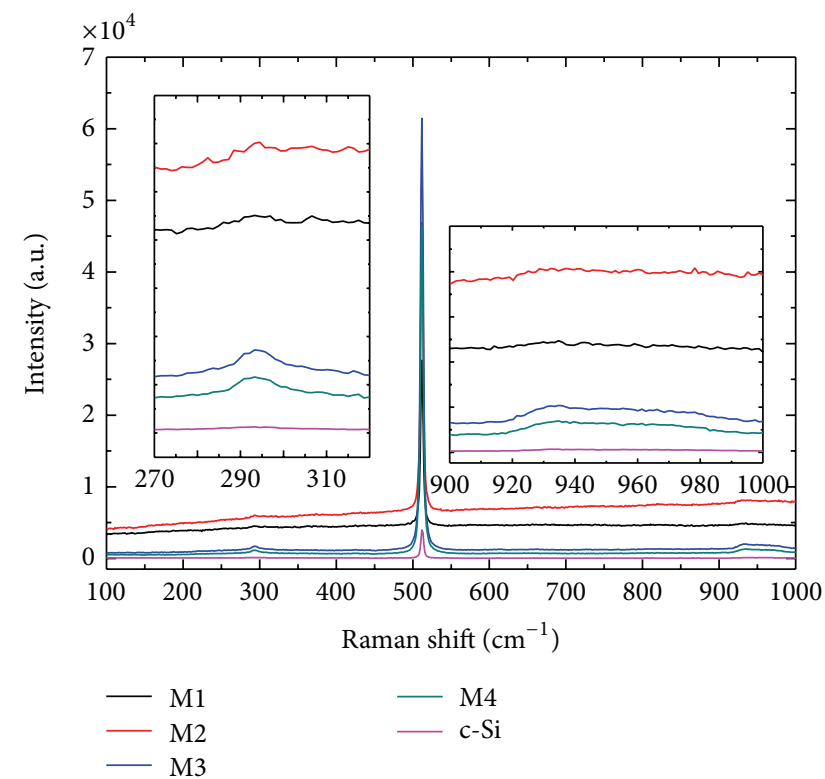

FIGURE 1: LO phonon Raman spectra of PS samples. Left inset shows Raman spectrum of PS samples in the range of $270-320 \mathrm{~cm}^{-1}$. Right inset shows spectrum in the range of $900-100 \mathrm{~cm}^{-1}$.

hydrogen peroxide. In other words, the peroxide generates or promotes the formation of disorder in the PSL. Left inset in Figure 1 shows the Raman spectra for PS samples from 270 to $320 \mathrm{~cm}^{-1}$. M3 and M4 show a broad peak around $290 \mathrm{~cm}^{-1}$. This peak arises due to the defect induced transverse acoustic phonon of c-Si [16]. This mode barely can be seen in M1 and M2 samples. This is consistent with our suggestion that the disordered silicon layer arises with the incorporation of hydrogen peroxide.

3.3. Photoluminescence in PS. Figure 2 shows the photoluminescence spectra of the PS samples. M1 and M2 samples had the higher photoluminescence intensities and also show an increase in the PL intensity with the increment in the anodization time. This increase is due to the formation of silicon nanocrystals present in the porous layer [17]. The main emission is centered around the $645 \mathrm{~nm}$, which is the PS characteristic emission and can be related to the presence of silicon nanocrystals in the porous layer [17]. M2 shows very few contributions around the 578 and $533 \mathrm{~nm}$. These emissions can be related to the thinning of the silicon nanocrystals due to the higher anodization time, which modifies the emission energy [18]. M3 and M4 samples show the lower PL intensities. The principal peak has a shift from

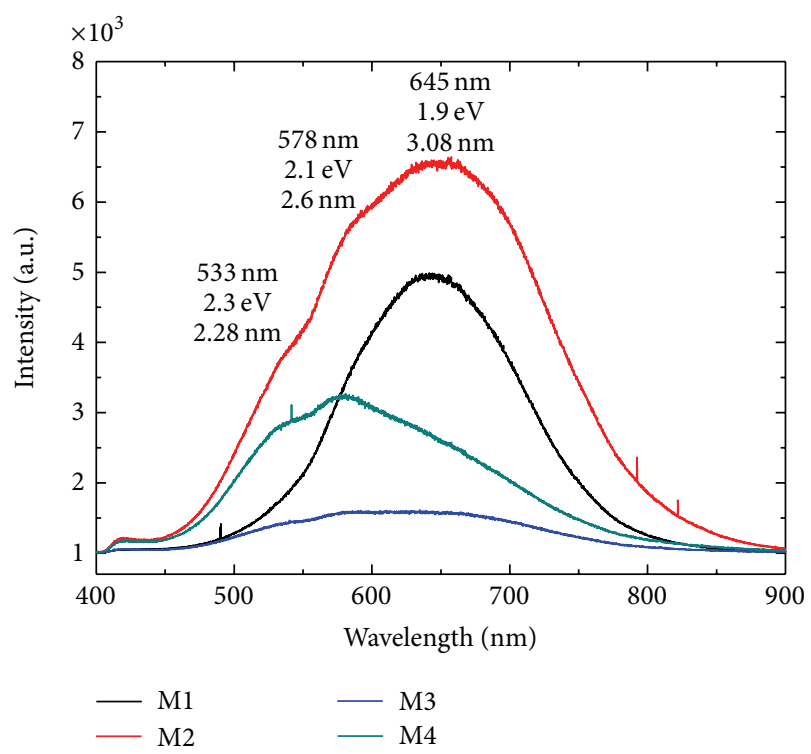

FIgURE 2: Photoluminescence spectra of PS samples. The image shows the nc-Si size calculated by (3).

the 645 to the $578 \mathrm{~nm}$. This shift can be caused by the formation of nonradiative recombination centers which are around the pores and is due to the hydrogen peroxide in the electrolyte. Moreover we can see that the contribution around $533 \mathrm{~nm}$ barely shows change and it takes importance, since it is almost equal in intensity to the emission centered at $578 \mathrm{~nm}$. These results suggest that the peroxide promotes the attack in the edges of the pores and thus is reflected in a thinning in the silicon nanocrystals, which originates the shift to low wavelengths.

Starting with the PL spectra the nc-Si size can be obtained. This parameter gives information about the changes that take place in the porous layer. For determining the approximate nc-Si size, the energy emission was related to the diameter of nc-Si $[15,19]$ through

$$
\left(\lambda(\mathrm{nm})=\frac{1.24 \mu}{E_{N}}=\frac{1.24 \mu}{\left(1.12+3.73 / d^{1.39}\right)}\right),
$$

where $d$ is the diameter of the nc-Si, $E_{N}$ is the energy associated to the $\mathrm{nc}-\mathrm{Si}$, and $\lambda(\mathrm{nm})$ is the wavelength of emission of the nc-Si. These theoretical values show a good approximation as Delerue et al. demonstrated [20]. Table 3 shows the results obtained by (3). The results show that the nc-Si size decreases with the anodization time for all samples, and we can see this in the PL spectra as a blueshift. For 

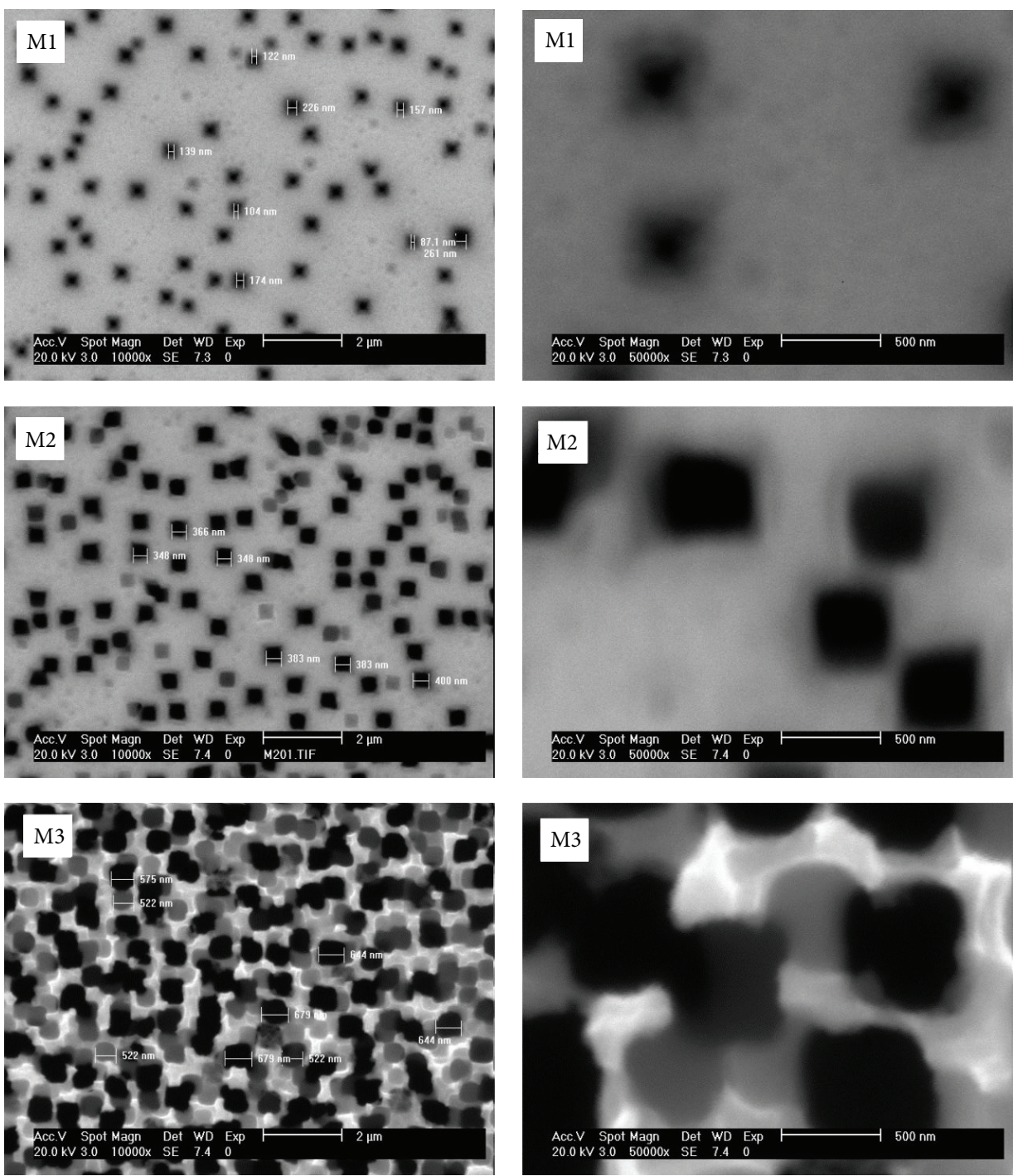

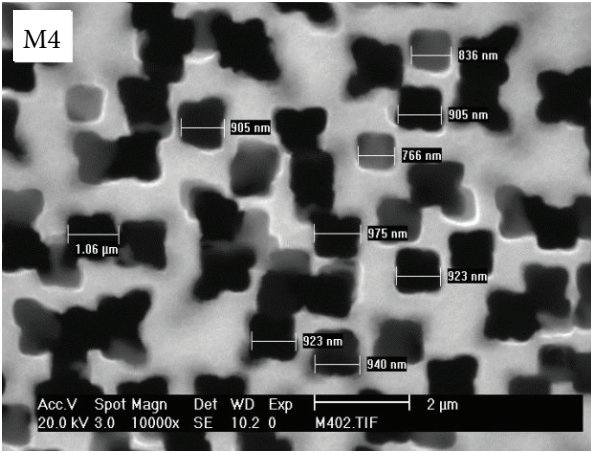

(a)

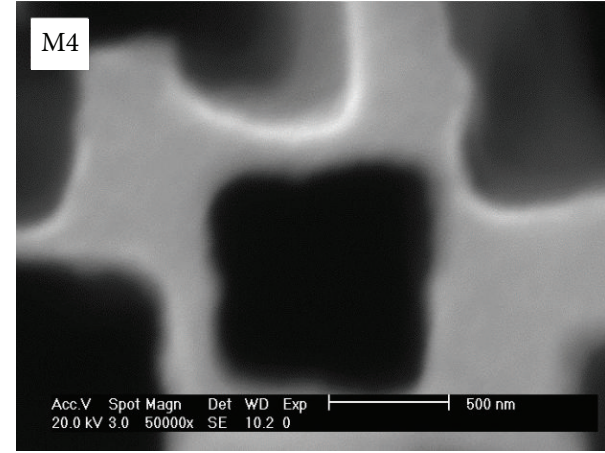

(b)

FIGURE 3: SEM images for the PS samples. In the images we can see the porous size in the different samples (a). Images on (b) show an approach to the pores, and in these images we can see the pore surroundings.

the M3 and M4 samples this shift is evident and is attributed to the change in the nc-Si size $[17,18]$. This change in the size is attributed to the hydrogen peroxide present in electrolyte and the anodization time.
3.4. Microstructure of PS from SEM. Scanning electron microscopy (SEM) images, Figure 3, show that in the M1 and M2 samples, the quantity and the pore size are bigger with the increase in the anodization time. With the increase of the 
TABLE 3: nc-Si size estimated through (3).

\begin{tabular}{lcc}
\hline Wavelength $(\mathrm{nm})$ & Energy $(\mathrm{eV})$ & nc-Si size \\
\hline 533 & 2.3 & 2.28 \\
578 & 2.1 & 2.6 \\
645 & 1.9 & 3.08 \\
\hline
\end{tabular}

quantity and porous size the PL presents a blueshift. This is related to the thinning of the nc-Si as we explained in the PL analysis, but it also can relate this shift to the electrolyte and the anodization time. For example, the M3 and M4 samples show an increase in the PL intensity as a function of the anodization time. This is related to the quantity of nc-Si present in the porous layer; besides, we can see the blueshift with the increment in the quantity and pore size, and this is clear in the change that present the emission centered at $645 \mathrm{~nm}$, which pass to the $578 \mathrm{~nm}$. Taking in consideration the nc-Si size calculated through PL spectra, we can reach the conclusion that the pores with the larger diameters contain the smaller nc-Si sizes. On the other hand, the samples obtained with hydrogen peroxide show the bigger pore diameters. This is indicative that the peroxide promotes the etching in the edges of the pores as can be seen in the SEM images and is reflected as an increased amount of disorder around pores as the Raman spectra demonstrated. Table 4 shows the pore size as a function of the electrolyte. This disorder also can produce nonradiative recombination centers, which is the reason that the samples obtained with hydrogen peroxide in the electrolyte show the lower PL intensities.

The chemical composition was obtained from the Energy Dispersive Spectrometer (EDS) spectrum, Table 5. M1 and M2 samples show an increase in the quantity of oxygen with the change in the anodization time, which can relate to the presence of oxygen with the PL intensity. The oxidation (presence of oxygen) favors the confinement of the nc-Si and this is reflected as an increase in the PL intensity. M3 and M4 samples show a quantity of oxygen that remains almost constant. In this case, the differences among the intensities are given by the quantity of nc-Si present in the porous layer. M4 sample has a larger amount due to the anodization time.

\section{Conclusions}

Samples obtained with the ratio $1: 2$ in the electrolyte show the higher PL intensities and the smaller pore sizes, which shows that the nc-Si in these pores have a bigger probability of PL emission. Raman spectra and SEM images showed that the rate of disorder increases when the pore diameter is bigger. The morphological analysis showed that the incorporation of $\mathrm{H}_{2} \mathrm{O}_{2}$ in the electrolyte increased the pore diameter. This is an important result for applications which need a big pore diameter, such as introducing molecules or medicines in the pores. Through the analysis of the PL we can see that the electrolyte with $\mathrm{H}_{2} \mathrm{O}_{2}$ promotes the thinning of the filaments and a lowering of the PL intensity.
TABLE 4: The samples obtained with hydrogen peroxide shows an increment in the quantity and porous size in comparison with the samples obtained without this.

\begin{tabular}{lcc}
\hline Sample & Electrolyte & Porous size \\
\hline M1 & $1: 2\left(\mathrm{HF} / \mathrm{CH}_{3}-\mathrm{CH}_{2}-\mathrm{OH}\right)$ & $87-226 \mathrm{~nm}$ \\
M2 & $1: 2\left(\mathrm{HF} / \mathrm{CH}_{3}-\mathrm{CH}_{2}-\mathrm{OH}\right)$ & $348-400 \mathrm{~nm}$ \\
M3 & $2: 1: 1\left(\mathrm{H}_{2} \mathrm{O}_{2} / \mathrm{HF} / \mathrm{CH}_{3}-\mathrm{CH}_{2}-\mathrm{OH}\right)$ & $522-679 \mathrm{~nm}$ \\
M4 & $2: 1: 1\left(\mathrm{H}_{2} \mathrm{O}_{2} / \mathrm{HF} / \mathrm{CH}_{3}-\mathrm{CH}_{2}-\mathrm{OH}\right)$ & $766 \mathrm{~nm}-1.06 \mu \mathrm{m}$ \\
\hline
\end{tabular}

TABLE 5: Chemical composition of the PS samples obtained from the EDS spectrum analysis.

\begin{tabular}{lcc}
\hline \multirow{2}{*}{ Sample } & \multicolumn{2}{c}{ Element $(\% \mathrm{~W})$} \\
& $\mathrm{Si}$ & $\mathrm{O}$ \\
\hline M1 [1:2 (HF/CH $\left.\left.-\mathrm{CH}_{2}-\mathrm{OH}\right)\right] 10 \mathrm{~min}$. & 90.4475 & 9.5525 \\
M2 [1:2(HF/CH $\left.\left.-\mathrm{CH}_{2}-\mathrm{OH}\right)\right] 15 \mathrm{~min}$. & 86.32 & 13.68 \\
M3 [2:1:1 $\left.\left(\mathrm{H}_{2} \mathrm{O}_{2} / \mathrm{HF} \mathrm{CH}_{3}-\mathrm{CH}_{2}-\mathrm{OH}\right)\right] 10 \mathrm{~min}$. & 90.3625 & 9.6375 \\
M4 [2:1:1 $\left.\left(\mathrm{H}_{2} \mathrm{O}_{2} / \mathrm{HF} / \mathrm{CH}_{3}-\mathrm{CH}_{2}-\mathrm{OH}\right)\right] 15 \mathrm{~min}$. & 91.31 & 8.69 \\
\hline
\end{tabular}

\section{Conflict of Interests}

The authors declare that there is no conflict of interests regarding the publication of this paper.

\section{Acknowledgments}

L. Castañeda gratefully acknowledges the financial support from the Escuela Superior de Ingeniería Mecánica y Eléctrica Unidad Ticomán, Instituto Politécnico Nacional, through Project no. 20150465. L. Castañeda also thanks Angel Maldonado Austria for useful discussions.

\section{References}

[1] L. T. Canham, "Silicon quantum wire array fabrication by electrochemical and chemical dissolution of wafers," Applied Physics Letters, vol. 57, no. 10, pp. 1046-1048, 1990.

[2] F. Severiano, G. García, and L. Castañeda, "Study of the electroluminescent properties of crystalline silicon wafers in devices based on junctions of indium-doped zinc oxide and porous silicon," Materials Science in Semiconductor Processing, vol. 27, pp. 326-334, 2014.

[3] F. Severiano, G. García, L. Castañeda, J. M. Gracia-Jiménez, H. Gómez-Pozos, and J. A. Luna-López, "Electroluminescent devices based on junctions of indium doped zinc oxide and porous silicon," Journal of Nanomaterials, vol. 2014, Article ID 409493, 7 pages, 2014.

[4] T. Tamura and S. Adachi, "Photo-oxidation effects of lightemitting porous Si," Journal of Applied Physics, vol. 105, no. 11, pp. 113518-113525, 2009.

[5] V. Lehmann and U. Gösele, "Porous silicon formation: a quantum wire effect," Applied Physics Letters, vol. 58, no. 8, pp. 856-858, 1991.

[6] M. S. Brandt, H. D. Fuchs, M. Stutzmann, J. Weber, and M. Cardona, "The origin of visible luminescencefrom 'porous silicon': a new interpretation," Solid State Communications, vol. 81, no. 4, pp. 307-312, 1992. 
[7] S. M. Prokes, "Study of the luminescence mechanism in porous silicon structures," Journal of Applied Physics, vol. 73, no. 1, pp. 407-413, 1993.

[8] R. W. Fathauer, T. George, A. Ksendzov, and R. P. Vasquez, "Visible luminescence from silicon wafers subjected to stain etches," Applied Physics Letters, vol. 60, no. 8, pp. 995-997, 1992.

[9] O. Bisi, S. Ossicini, and L. Pavesi, "Porous silicon: a quantum sponge structure for silicon based optoelectronics," Surface Science Reports, vol. 38, no. 1, pp. 1-126, 2000.

[10] A. Halimaoui, C. Oules, G. Bomchil et al., "Electroluminescence in the visible range during anodic oxidation of porous silicon films," Applied Physics Letters, vol. 59, no. 3, pp. 304-306, 1991.

[11] S. Y. Ren and J. D. Dow, "Hydrogenated Si clusters: band formation with increasing size," Physical Review B, vol. 45, no. 12, pp. 6492-6496, 1992.

[12] R. R. Koropecki, R. Arce, C. Spies, A. M. Gennaro, and J. Schmidt, "Role of hydrogen in the photoinduced evolution of porous silicon luminescence," Physica Status Solidi (C) Current Topics in Solid State Physics, vol. 4, no. 6, pp. 2150-2154, 2007.

[13] J. J. Yon, K. Barla, R. Herino, and G. Bomchil, "The kinetics and mechanism of oxide layer formation from porous silicon formed on p-Si substrates," Journal of Applied Physics, vol. 62, no. 3, pp. 1042-1048, 1987.

[14] Z. Sui, P. P. Leong, I. P. Herman, G. S. Higashi, and H. Temkin, "Raman analysis of light-emitting porous silicon," Applied Physics Letters, vol. 60, no. 17, pp. 2086-2088, 1992.

[15] E. Edelberg, S. Bergh, R. Naone, M. Hall, and E. S. Aydil, "Luminescence from plasma deposited silicon films," Journal of Applied Physics, vol. 81, no. 5, pp. 2410-2417, 1997.

[16] R. Prabakaran, R. Kesavamoorthy, and A. Singh, "Optical and microstructural investigations of porous silicon," Bulletin of Materials Science, vol. 28, no. 3, pp. 219-225, 2005.

[17] G. G. Qin and Y. J. Li, "Photoluminescence mechanism model for oxidized porous silicon and nanoscale-silicon-particleembedded silicon oxide," Physical Review B-Condensed Matter and Materials Physics, vol. 68, no. 8, Article ID 085309, pp. 1-7, 2003.

[18] G. G. Qin, "Multiple mechanism model for photoluminescence from oxidized porous Si," Physica Status Solidi A, vol. 182, no. 1, pp. 335-339, 2000.

[19] G.-R. Lin, C.-J. Lin, C.-K. Lin, L.-J. Chou, and Y.-L. Chueh, "Oxygen defect and Si nanocrystal dependent white-light and near-infrared electroluminescence of Si-implanted and plasmaenhanced chemical-vapor deposition-grown Si-rich $\mathrm{SiO}_{2}$," Journal of Applied Physics, vol. 97, no. 9, Article ID 094306, 2005.

[20] C. Delerue, G. Allan, and M. Lannoo, "Theoretical aspects of the luminescence of porous silicon," Physical Review B, vol. 48, no. 15, pp. 11024-11036, 1993. 

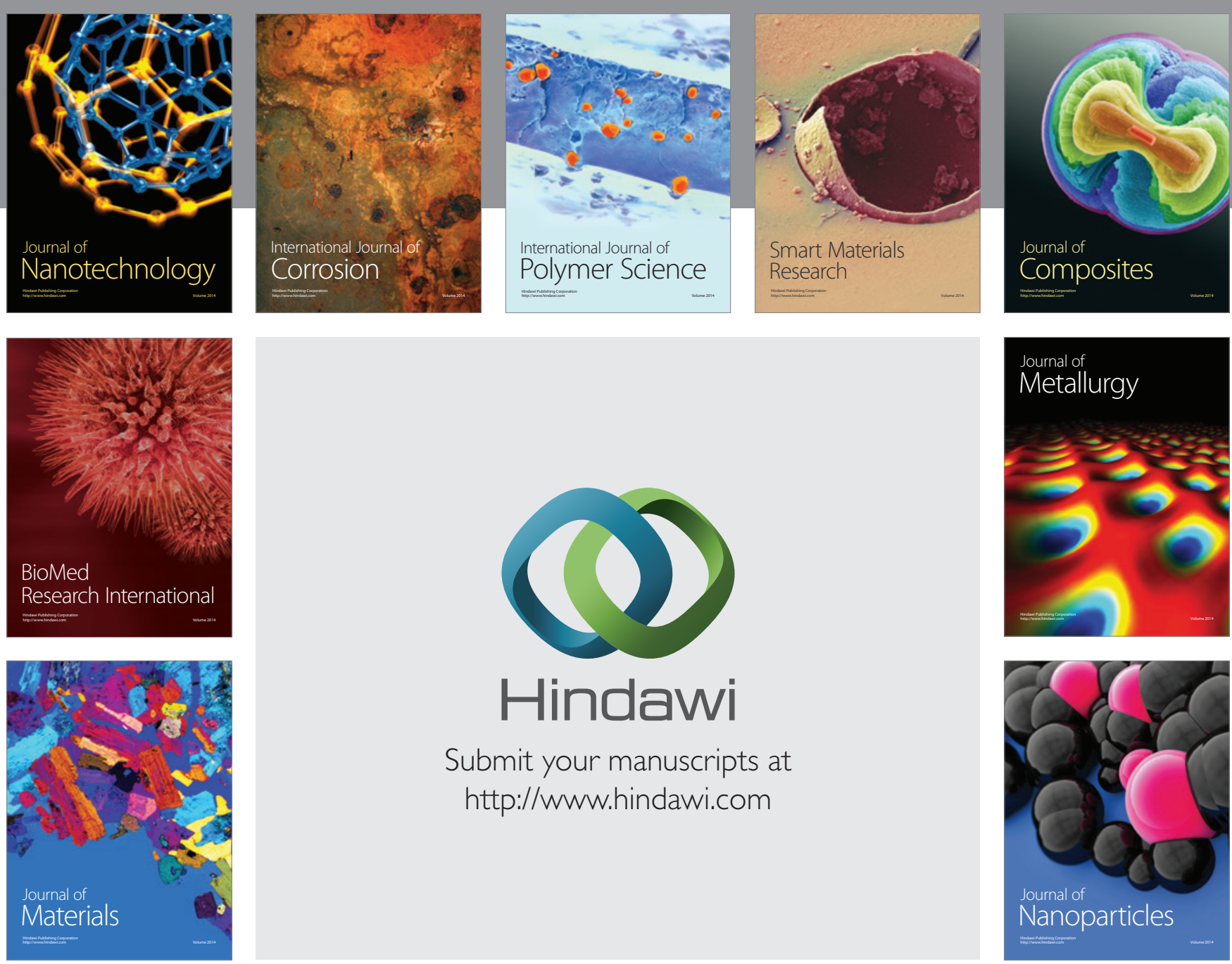

Submit your manuscripts at http://www.hindawi.com
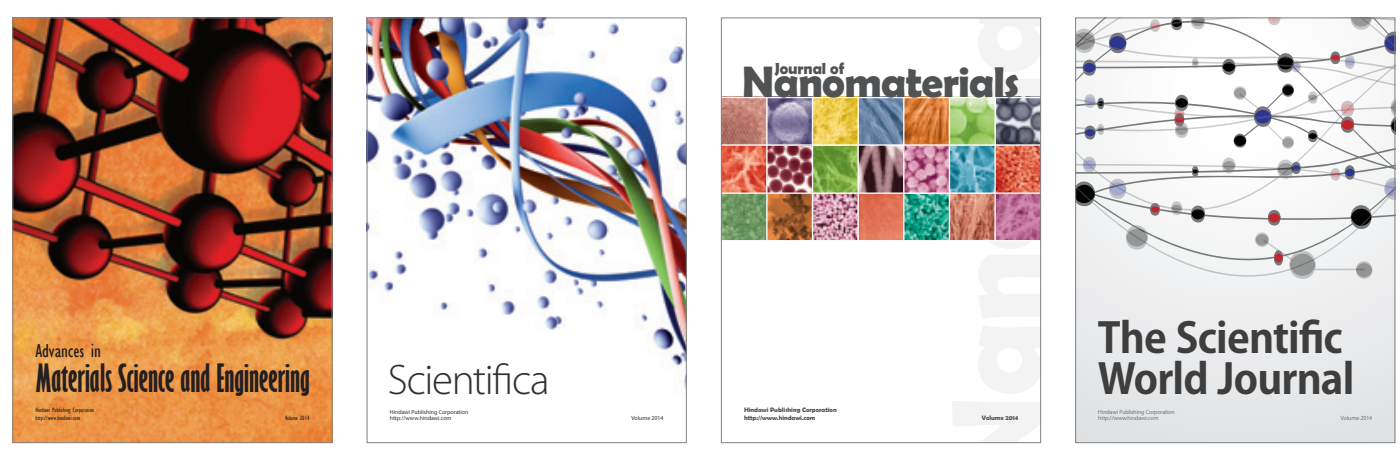

\section{The Scientific World Journal}
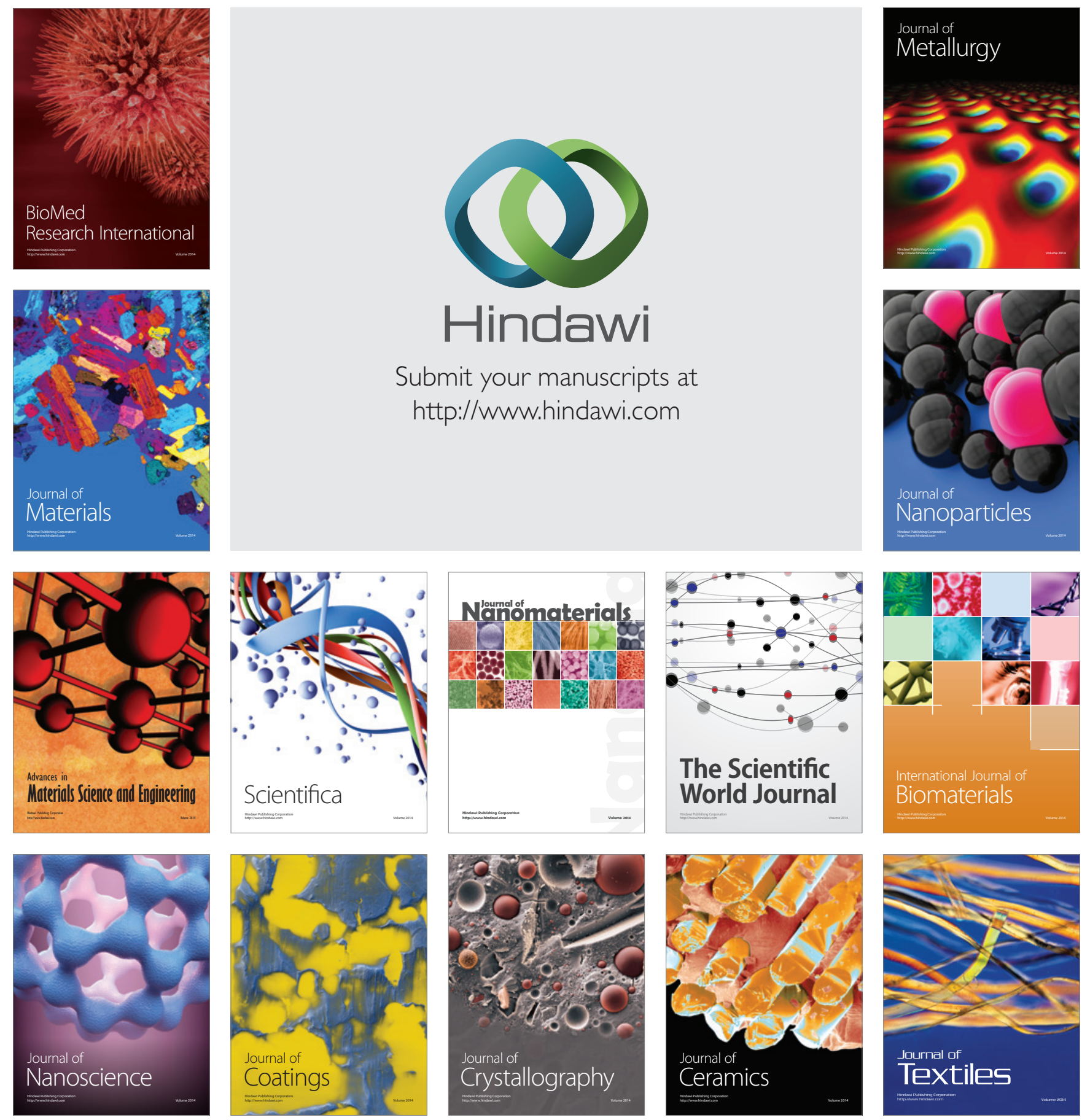